\title{
The interrelatedness between infants' communicative gestures and lexicon size: A longitudinal study
} \author{
Fernanda Leopoldina Viana ${ }^{\mathrm{d}}$ \\ ${ }^{\text {a }}$ Research Centre on Child Studies, University of Minho, Portugal \\ b Psychology Research Centre, University of Minho, Portugal \\ c School of Psychology, University of Minho, Portugal \\ ${ }^{\mathrm{d}}$ Institute of Education, University of Minho, Portugal
}

Irene Cadime $^{a, *}$, Carla Silva ${ }^{a}$, Sandra Santos ${ }^{b}$, Iolanda Ribeiro ${ }^{c}$,

\section{A R T I C L E I N F O}

\section{Keywords:}

MacArthur-Bates communicative development inventory

Gestures

Word production

Word comprehension

\begin{abstract}
A B S T R A C T
Research has shown a close relationship between gestures and language development. In this study, we investigate the cross-lagged relationships between different types of gestures and two lexicon dimensions: number of words produced and comprehended. Information about gestures and lexical development was collected from 48 typically developing infants when these were aged 0;9, 1;0 and 1;3. The European Portuguese version of the MacArthur-Bates Communicative Development Inventory: Words and Gestures (PT CDI:WG) was used. The results indicated that the total number of actions and gestures and the number of early gestures produced at 0;9 and at 1;0 year predicted the number of words comprehended three months later. Actions and gestures' predictive power of the number of words produced was limited to the $0 ; 9-1 ; 0$ year interval. The opposite relationship was not found: word comprehension and production did not predict action and gestures three months later. These results highlight the importance of non-verbal communicative behavior in language development.
\end{abstract}

\section{Introduction}

Infants' communicative development involves a series of verbal and non-verbal behaviors. The development of both dimensions has been frequently described as closely related given that the attainment of several milestones in gestural communication and language acquisition seem to overlap (Bates \& Dick, 2002). Word comprehension precedes word production, as children already comprehend several words (usually words linked to people, routines, sound effects or animal sounds) at 0;8-0;9 (Bleses et al., 2008b; Kern, 2007), whereas the production of the first words usually occurs around the children's first birthday (Bates et al., 1994; Bleses et al., 2008a; Wehberg et al., 2007). Additionally, most of the children already communicate using non-verbal behaviors, i.e. actions and gestures, before they start to produce their first words (Iverson \& Goldin-Meadow, 2005). Deictic gestures, such as pointing or show, have been observed in such early ages as 0;8-0;10 (Bates, Benigni, Bretherton, Camaioni, \& Volterra, 1979; Bates \& Dick, 2002; Brooks \& Meltzoff, 2008). Therefore, in the early stages of development, gestures are a mean to communicate information that the children are not yet able to express verbally (e.g., extend the hand to request an object as they are not yet able to ask for it). However, even after the first words onset, the gesture production still accompanies the word production. The production of a gesture while

\footnotetext{
* Corresponding author at: Centro de Investigação em Estudos da Criança, Instituto de Educação, Universidade do Minho, Campus de Gualtar, $4710-057$ Braga, Portugal.

E-mail address: irenecadime@ie.uminho.pt (I. Cadime).
} 
speaking seem to serve as a mean to establish the connection between the word and the referent, such as when the children points an object while saying its name or shows an object while saying 'look' (Iverson \& Goldin-Meadow, 2005). Deictic gestures are often labeled as early gestures, a category that also includes routine and conventional gestures (e.g. waving to indicate 'bye-bye' or shaking the head for 'yes') which are assimilated through imitation in social interaction (Bavin et al., 2008; Fenson et al., 2007; JacksonMaldonado et al., 2003).

Other types of non-verbal communicative behaviors are object-related actions, sometimes called object gestures, recognitory gestures, gestural names or event schemas (Capone \& McGregor, 2004; Kraljević, Cepanec, \& Šimleša, 2014). These refer to actions in which a child uses one object (real or imaginary) to perform one specific action, such as put the telephone to ear (or a similar object such as a TV remote control), and involve some degree of symbolic representation or 'schemas' related with the object function (Bavin et al., 2008; Kraljević et al., 2014). The ability to perform object-related actions seems to emerge slightly later than early gestures. Using a longitudinal design, Sansavini et al. (2010) assessed monthly an Italian speaking sample of infants, from ages 0;10 to 1;5, using the Italian CDI short version. They found that some early gestures were already observed at $0 ; 10(M=3.05$, SD $=1.36)$, whereas object-actions were scarce at this age stage $(M=0.91, \mathrm{SD}=1.11)$ (Sansavini et al., 2010). However, they also found that different types of object-actions seemed to emerge at different rates: actions with concrete objects appeared earlier than actions involving more abstract symbolic representations, such as the actions performed when pretending to be a parent using a puppet and imitating adults' actions with objects. Actions with objects usually start to be produced by children around their first birthday (Capone \& McGregor, 2004; Caselli, Rinaldi, Stefanini, \& Volterra, 2012). Thus, this particular type of gestures emerges approximately at the same time as word production, and both competences are highly correlated at early stages of communicative development: the earlier the child produces the gestures, the earlier he/she will start talking (Shore, Bates, Bretherton, Beeghly, \& O'Connell, 1990). Additionally, these gestures and the first words are similar in content as they usually refer to the same actions and objects, mainly related with "eating, drinking, greeting, bathing, dressing, household activities, vehicles, appearance and disappearance of objects" (Bates \& Dick, 2002, p. 295).

The results from the validation studies of the MacArthur-Bates Communicative Development Inventories: Words and Gestures (CDI: WG) for different languages, with children aged approximately 0;8-1;6, indicate moderate-to-high correlations between gestures, word comprehension and word production, but the associations between gestures and word comprehension (ranging approximately between .73 and .79) are stronger than the ones between gestures and word production (ranging approximately between .37 and .50) (Fenson et al., 2007; Kern, 2007; López-Ornat et al., 2005). Similar results were found in the previously referred study by Sansavini et al. (2010): the number of gestures produced was significantly correlated with the number of words comprehended at $0 ; 10,0 ; 11$ and $1 ; 5$ and correlated with the number of words produced at $1 ; 2$ and $1 ; 3$, but the correlations between gestures and comprehension were slightly stronger. The number of object-actions produced was correlated with the number of words comprehended at almost all months of age, but no significant correlations with the number of words produced were found (Sansavini et al., 2010).

Research has also provided evidence for longitudinal associations between gestures and lexical development. The presence of specific gestures has been associated to future language skills. For example, Brooks and Meltzoff (2008) found that spontaneous infant pointing at $0 ; 10-0 ; 11$ predicted the vocabulary growth up to $2 ; 0$ years. This predictive power was also verified when a varied number of early gestures and object-actions were considered. For example, results from a longitudinal study conducted in Australia with the CDI: WG (Bavin et al., 2008) indicated that: (a) the number of different gestures produced at 0;8 predicted word production and comprehension at $1 ; 0$ and word production at 2;0 years; and (b) the number of different gestures produced at 1;0 predicted word production at 2;0 years. However, the percentage of variance explained was higher for the word comprehension dimension than for the word production dimension, and this was especially notorious when the number of object-actions was used as predictor.

These findings are consistent with the argument that language emerges from the skills involved in gesture and tool use, such as attention, perception, imitation and symbolic processing (Bates \& Dick, 2002), which can explain the predictive power of actions and gestures on future language comprehension and production. Additionally, the use of some specific gestures by the children, particularly deictic ones, can foster adult-child interaction and child-directed speech, which, in turn, promote children's language. As Brooks and Meltzoff (2008) indicate, "the benefit to vocabulary growth may be that infants' pointing promotes increased word learning opportunities. An infant's point is an invitation for a word: parents label what infants point at" (p. 217). Early gestures such as pointing, showing or giving are crucial in joint activities where children and adults attend conjointly to the same event or object: these gestures not only can be an initiation to joint attention, but also allow children to express shared mental representations with the adult (Carpenter, Nagell, \& Tomasello, 1998; Nelson, 2007). Moreover, neuropsychological studies have also found evidence that language and gestures share common neural substrates (Gentilucci \& Dalla Volta, 2007).

Studies using the CDI have indicated that children are still acquiring new actions and gestures at least up to 1;6 (Caselli et al., 2012; Sansavini et al., 2010). If a common neural subtract exists and if both gestures and language require a common set of cognitive skills, it is also possible that language skills predict actions and gestures at this age stage. Most of the studies that investigate the relationship between gestures and lexical development are correlational (Bates, Thal, Whitesell, Fenson, \& Oakes, 1989; Kern, 2007; Kraljević et al., 2014; Sansavini et al., 2010). Cross-lagged panel designs are an alternative to correlational studies, as they allow testing for the directionality of the relationships between the variables and, therefore, to understand if these are reciprocal (Selig \& Little, 2012). This type of analysis was used in one study by Carpenter et al. (1998) to investigate the longitudinal relationships between gestures and language. They followed monthly a sample of English-speaking infants from 0;9 to 1;3, using direct measures of the infants' communicative gestures and language (number of referential words, i.e. used for concrete objects or actions) produced during an experimental task in laboratory. They found that communicative gestures at 0;9 predicted language skills at $1 ; 1$ and at $1 ; 2$ but language did not predict the number of communicative gestures. 
The main goal of our study was to investigate if the relationship between gestures (total number, early and later gestures) and language (comprehension and production) is reciprocal, using a cross-lagged panel design and a sample of European Portuguesespeaking infants assessed from $0 ; 9$ to $1 ; 3$. We expect to find results similar to the ones obtained in previous studies conducted with the same instrument (CDI) in different languages and cultures (Bavin et al., 2008; Sansavini et al., 2010), meaning that we expect that the number of actions and gestures produced predict the number of words comprehended and produced some months later. To our knowledge, no study using the CDI tested the opposite relationship. However, following the results obtained in the study by Carpenter et al. (1998), which used direct measures of the children's skills, we expect to obtain similar results using the CDI, meaning that the language skills do not predict the number of actions and gestures produced a few months later. Therefore, the first two hypotheses of this study were: $\mathrm{H} 1$ - The number of actions and gestures (total number, early gestures and later gestures) produced at 0;9 and 1;0 predicts the number of words comprehended three months later but not the opposite; $\mathrm{H} 2$ - The number of actions and gestures (total number, early gestures, and later gestures) produced at 0;9 and 1;0 predicts the number of words produced three months later but not the opposite. Given that studies using the CDI have generally found a closer association between actions and gestures and word comprehension (Bavin et al., 2008; Caselli et al., 2012; Fenson et al., 2007; Kern, 2007; Sansavini et al., 2010), we also expect to verify similar results in our study. Therefore, the third hypothesis of this study was: H3 - The total number of actions and gestures, the number of early gestures and the number of later gestures are strongest predictors of the number of words comprehended than of the number of words produced.

\section{Method}

\subsection{Participants and procedure}

The participants were recruited in the validation study of the Portuguese version of the MacArthur-Bates Communicative Development Inventory: Words and Gestures [PT CDI:WG] (Silva et al., 2017). The questionnaires used in the validation study included a field asking the parents if they were available to participate in a longitudinal study. All the cases $(N=108)$ that fulfilled the following two conditions were registered in a database: (a) the infants were 0;9 at the time that the CDI was filled; and (b) the parents indicated that they were willing to participate in the longitudinal study and provided a valid contact (phone and/or email). Subsequently, the 108 parents were contacted by phone or email and the specific procedures of the study were explained to them. Following this contact, 105 parents agreed to participate. About one day before each infant turned 1;0 and 1;3, the researchers sent the PT CDI:WG to these parents by mail. The parents were asked to fill the instrument as soon as possible and to return it also by mail using a pre-paid envelope that was also sent them. Forty two participants did not returned the filled inventory at time $2(1 ; 0)$ and 15 did not returned the inventory at time $3(1 ; 3)$. All these participants were then excluded from the study. Given that the participants were recruited in the validation study of the PT CDI:WG, the same exclusion criteria were applied: children born prematurely with low weight (less than 32 weeks of pregnancy and 1500 grams), children whose both parents were not European Portuguese speakers and children with severe medical conditions that could result in language impairment.

Therefore, the final sample consisted of 48 typically developing infants, which were assessed at three months intervals, when they were aged 0;9, 1;0 and 1;3. Regarding gender distribution, 28 were boys and 20 were girls. Only four children did not attend daycare at time $1(0 ; 9)$. Three of them did not enter daycare until the end of the study, i.e., when they were $1 ; 3$. The fourth child entered daycare at $1 ; 2$. The remaining children had on average three months of daycare attendance (Mean $=3.00$; SD $=1.24$; Range: $0-5$ ). The participants were from all regions of Portugal, and the percentage of participants from each region was very similar to the one observed for the general population (see Table 1). Regarding maternal education, most of the mothers $(n=32)$ had a higher education degree. Half of the children's fathers $(n=24)$ completed high school or less and about other half $(n=22)$ completed a higher education degree (no information collected for 2 cases). The CDI was filled by the infants' mother in the majority of the cases $(n=40)$. In a small number of cases the CDI was filled by the father $(n=4)$ or by the mother and father together $(n=4)$.

Table 1

Distribution of the participants by the seven regions of Portugal.

\begin{tabular}{llcc}
\hline Region & Sample & & General population in Portugal (\%) \\
\cline { 2 - 4 } & $n$ & $\%$ & 34.9 \\
\hline North & 23 & 47.9 & 21.8 \\
Center & 10 & 20.8 & 27.1 \\
Lisbon & 9 & 18.7 & 7.0 \\
Alentejo & 2 & 4.2 & 4.3 \\
Algarve & 2 & 4.2 & 2.4 \\
Madeira & 1 & 2.1 & 2.5 \\
Azores & 1 & 2.1 & \\
\hline
\end{tabular}

Note: Statistics for the general population retrieved from Census 2011. 


\subsection{Measures}

The Portuguese version of the MacArthur-Bates Communicative Development Inventory: Words and Gestures (Silva et al., 2017) was used to collect information on gestures, actions with objects and lexical development (comprehension and production). In all sections of the PT CDI:WG, the parents are asked to complete the items according to the infant's perceived competences.

Two mains sections compose the PT CDI:WG: (1) early words and (2) actions and gestures. The "Early words" section is divided into four parts: (a) First signs of understanding; (b) Phrases; (c) Starting to talk; and (d) Vocabulary checklist. For purposes of this study, only the vocabulary checklist was considered. The 317 items that compose it are grouped into 20 categories: Interjections, animal and object sounds; Animals; Vehicles; Toys; Food and drink; Clothing; Body parts; Small household items; Furniture and rooms; Outdoor elements; Places to go; People; Words for games, routines and greetings; Verbs; Descriptive words; Words about time; Possessive, demonstrative and personal pronouns, and contraction of prepositions and pronouns; Question words; Adverbs; and Quantifiers. The instructions indicate that parents should mark the words that their child "understands" or "understands and says", even if his/her pronunciation of the word is not totally correct. The items marked as "understands" or "understands and says" are summed to obtain a total of word comprehension. The items marked as "understands and says" are summed to obtain a total of word production.

The "Action and gestures" section is composed of 60 items divided into six parts: (a) First communicative gestures (13 items); (b) Games and routines (1 item); (c) Actions with objects (17 items); (d) Pretending to be a parent (13 items); (e) Imitating other adult actions (15 items); and (f) Actions with an object instead of other (1 item). The section "(a) First communicative gestures" comprises deictic gestures (e.g. show, point), routine gestures (e.g. blow a kiss), and conventional gestures (e.g. places the finger over the lips to ask for silence, shakes the head for 'no') and the parents should indicate if the child uses each gesture using the following response scale: "not yet"; "sometimes"; "often". The section "(b) Games and routines" analyses the active participation in interactive games between the adult and the child. The section "(c) Actions with objects" is composed of recognitory gestures such as "eats with spoon or fork'. The sections “(d) Pretending to be a parent", “(e) Imitating other adults actions" and "(f) Actions with an object instead of other" include gestures related with symbolic representations, such as '[pretends to be a parent by] kissing a puppet' (section d), 'Sweeps with broom or mop' (section e) or 'uses the TV remote control as a telephone" (section f). In sections (b) to (f), the parents must indicate if the child performs the action using a dichotomous scale ("yes"/"no"). Regarding scoring, a score of 1 is given for each item checked in the sections "Games and routines", "Actions with objects, "Pretending to be a parent", and "Imitating other adults' actions". In the section "First communicative gestures", responses "not yet" are scored zero and responses "sometimes" or "often" are scored 1. A score for total actions and gestures produced is obtained by summing the scores in sections (a) to (f). Additionally, a score for early gestures can be computed by adding the scores in sections (a) and (b) and a score for later gestures can be computed by adding the scores in sections (c), (d), (e) and (f). The later gestures' dimension comprises what has been designated as object-related actions in other studies (e.g., Sansavini et al., 2010).

In the validation study of the PT CDI:WG (Silva et al., 2017), very high internal consistency values were obtained for word comprehension $(\alpha=.99)$, word production $(\alpha=.97)$, and actions and gestures $(\alpha=.95)$ subscales. The correlations between the three subscales were positive and high, ranging between .481 and .639 for girls and between .503 and .687 for boys (Silva et al., 2017).

\subsection{Statistical analyses}

Descriptive statistics (mean, standard deviation and range) and Pearson correlation coefficients were computed for word comprehension, word production, total actions and gestures, first gestures and later gestures in the three age stages. The prospective relationships between the lexical and the gestures dimensions were analyzed by testing cross-lagged models, using Mplus version 7 (Muthén \& Muthén, 2012). The maximum likelihood estimator was used. Fig. 1 depicts the relationships tested in each of six models. In each one, the relationships between one score (V1) of actions and gestures (total score, number of early gestures or number of later gestures) and one score (V2) of lexicon size (word comprehension or word production) were tested. The models included the paths for

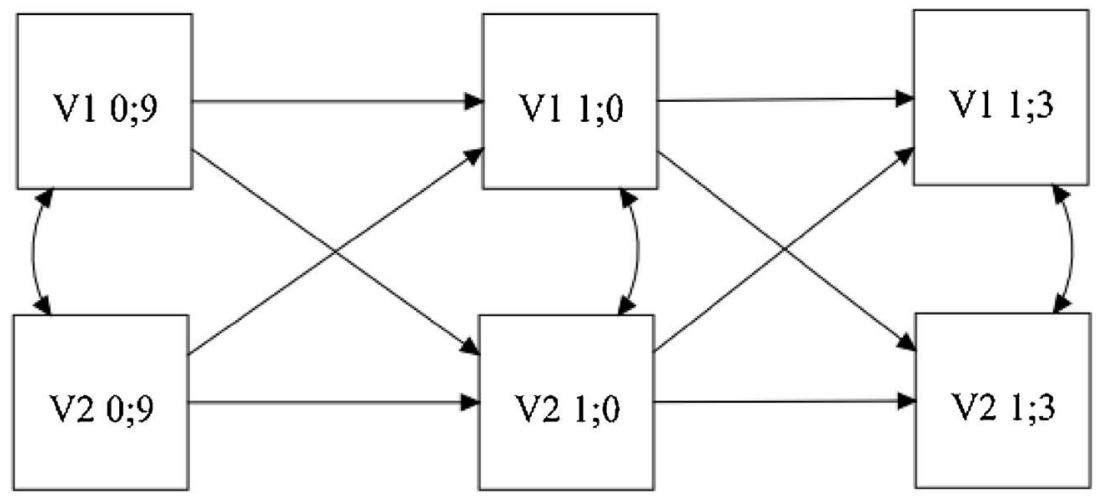

Fig. 1. Depiction of the tested cross-lagged relationships between lexical and gestures dimensions. 
Table 2

Descriptive statistics for the observed scores in word comprehension, word production and actions and gestures.

\begin{tabular}{|c|c|c|c|}
\hline \multirow[t]{2}{*}{ Variables } & \multicolumn{3}{|c|}{ Age } \\
\hline & $0 ; 9$ & $1 ; 0$ & $1 ; 3$ \\
\hline \multicolumn{4}{|c|}{ Word comprehension } \\
\hline Mean (SD) & $41.54(53.83)$ & $84.69(75.32)$ & $141.33(82.05)$ \\
\hline Range & $0-288$ & $1-314$ & $13-316$ \\
\hline$N$ & 48 & 48 & 48 \\
\hline \multicolumn{4}{|c|}{ Word production } \\
\hline Mean (SD) & $0.75(1.98)$ & $4.25(6.40)$ & $17.10(19.36)$ \\
\hline Range & $0-10$ & $0-25$ & 0-102 \\
\hline$N$ & 48 & 48 & 48 \\
\hline \multicolumn{4}{|c|}{ Total actions and gestures } \\
\hline Mean (SD) & $10.44(6.47)$ & $21.09(7.48)$ & $34.44(7.24)$ \\
\hline Range & $2-28$ & $8-38$ & $18-51$ \\
\hline$N$ & 41 & 44 & 41 \\
\hline \multicolumn{4}{|l|}{ Early gestures } \\
\hline Mean (SD) & $6.43(2.86)$ & $9.38(2.51)$ & $11.89(1.57)$ \\
\hline Range & $2-14$ & $4-14$ & $8-14$ \\
\hline$N$ & 42 & 45 & 45 \\
\hline \multicolumn{4}{|l|}{ Later gestures } \\
\hline Mean (SD) & $3.70(4.12)$ & $11.62(5.74)$ & $22.40(6.39)$ \\
\hline Range & $0-16$ & $3-26$ & $6-37$ \\
\hline$N$ & 46 & 47 & 42 \\
\hline
\end{tabular}

Note: $\mathrm{SD}=$ Standard deviation.

each variable from $0 ; 9-1 ; 3$, and the path from variable 1 at $0 ; 9$ to variable 2 at $1 ; 0$, the path from variable 2 at $0 ; 9$ to variable 1 at $1 ; 0$, the path from variable 1 at $1 ; 0$ to variable 2 at $1 ; 3$, and the path from variable 2 at $1 ; 0$ to variable 1 at $1 ; 3$ (see Fig. 1). The following criteria were used to evaluate model fit: the chi-square $\left(\chi^{2}\right)$ value, the ratio $\chi^{2} / \mathrm{df}$, the Comparative Fit Index (CFI), the Tucker-Lewis Index (TLI), the Root Mean Square Error of Approximation (RMSEA) and the Standardized Root Mean Square Residual (SRMR). Values for the ratio $\chi^{2}$ /df below 3.00 are generally considered indicators of an acceptable fit and below 2.00 indicators of a good model fit (Bollen, 1989). Model fit is also considered acceptable when CFI and TLI values are above .90 and considered good when these are above .95 (Hoyle \& Panter, 1995; Hu \& Bentler, 1999). RMSEA below .08 and SRMR below .10 also indicate acceptable model fit, whereas values below .05 suggest good fit (Browne \& Cudeck, 1993; Schermelleh-Engel, Moosbrugger, \& Müller, 2003).

Fifteen cases had incomplete data in the "Actions and Gestures" section (see Table 2 for the number of missing values in each variable). Little's (1988) MCAR test was non-significant, $\chi^{2}{ }_{(121)}=28.486, p=1.00$, indicating that the pattern of missingness was completely random. Full information maximum likelihood (FIML) was used to account for missing data. FIML uses all the data available to estimate the model, without imputing data.

\section{Results}

Table 2 provides the descriptive statistics for the scores of each measured variable. The average number of words comprehended increased from 42 at $0 ; 9$ to 141 at $1 ; 3$. Words produced were scarce at $0 ; 9$ but children produced an average of 4 words at $1 ; 0$ and 17 at $1 ; 3$. The inter-individual variability was also very high, especially at $1 ; 3$ (see Table 2). Children already produced several early gestures at 0;9 (six on average) and the number increased to the double at 1;3 (12 on average). Later gestures were not so frequent as early gestures at 0;9. However, their production increased steadily and children produced on average 22 of the later gestures contained in the PT CDI:WG at $1 ; 3$.

Table 3 presents the correlation matrix among the two lexical dimensions (word comprehension and production) and the scores in actions and gestures in the three age stages. Word comprehension at 0;9 was not correlated with the total number of actions and gestures and with later gestures at $1 ; 3$. Word production at $0 ; 9$ was also not correlated with total actions and gestures, early gestures and later gestures at $1 ; 3$, nor with later gestures at $0 ; 9$. No relationship was also found between later gestures at 1;0 and early gestures at 1;3. All other correlations were positive and significant. The correlations between word comprehension and total actions and gestures measured at the same months of age ranged between .579 and .684 , whereas the correlations between word production and total actions and gestures measured at the same months of age ranged between .306 and .510 .

Model 1 tested the cross-lagged relationships between word comprehension and total number of actions and gestures produced. The model had a good fit, $N=41, \chi^{2}(4)=4.486, p=.352, \chi^{2} / \mathrm{df}=1.122$, RMSEA $=.051$ [90\% CI: .000-.246], CFI $=.998$, $\mathrm{TLI}=.992$, SRMR $=.021$. As can be seen in Fig. 2 , the total number of actions and gestures produced at 0;9 and at $1 ; 0$ predicted the number of words comprehended three months later. The prediction was stronger from $0 ; 9$ to $1 ; 0$ than from $1 ; 0$ to $1 ; 3$. The number of words comprehended did not predict the number of actions and gestures at any stage (see Fig. 2).

Model 2 tested the cross-lagged relationships between the number of words comprehended and the number of early gestures produced. The model had a good fit, $N=42, \chi^{2}(4)=2.751, p=.600, \chi^{2} / \mathrm{df}=0.688$, RMSEA $=.000$ [90\% CI: .000-.196], $\mathrm{CFI}=1.00, \mathrm{TLI}=1.00, \mathrm{SRMR}=.013$. Similarly to the previous model, early gestures at $0 ; 9$ predicted word comprehension at $1 ; 0$ 
Table 3

Correlation matrix for the observed scores in word comprehension, word production and actions and gestures.

\begin{tabular}{|c|c|c|c|c|c|c|c|c|c|c|c|c|c|c|c|}
\hline & WC $0 ; 9$ & WC $1 ; 0$ & WC $1 ; 3$ & WP $0 ; 9$ & WP $1 ; 0$ & WP $1 ; 3$ & TAG $0 ; 9$ & TAG $1 ; 0$ & TAG $1 ; 3$ & EG $0 ; 9$ & EG $1 ; 0$ & EG $1 ; 3$ & LG $0 ; 9$ & LG $1 ; 0$ & LG $1 ; 3$ \\
\hline WC 0;9 & 1 & $.819^{\text {*炏 }}$ & $.645^{\text {thkx }}$ & $.371^{* * *}$ & $.510^{\text {w.knke }}$ & $.379^{* * *}$ & $.684^{\text {kwx }}$ & $.380^{*}$ & .307 & 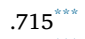 & $.414^{* * *}$ & $.388^{\text {ink }}$ & $.576^{\text {k*x/x}}$ & $.312^{*}$ & .279 \\
\hline WC $1 ; 0$ & & 1 & $.841^{k * * *}$ & $.500^{* \ldots * k}$ & $.671^{* \ldots \ldots k}$ & $.602^{* * *}$ & $.804^{* * * * x}$ & $.579^{* * *}$ & $.524^{k * k * k}$ & $.764^{* * * *}$ & $.474^{* * *}$ & $.403^{* k x}$ & $.717^{* * * x}$ & $.541^{* * * * *}$ & $.516^{* * * x}$ \\
\hline WC $1 ; 3$ & & & 1 & $.431^{* * k}$ & $.578^{* * * * k}$ & $.571^{* * * *}$ & $.696^{* * * *}$ & $.603^{* * * *}$ & $.666^{* * * *}$ & $.727^{\text {k***x}}$ & $.527^{2+x+k}$ & $.434^{* * *}$ & $.587^{* * * *}$ & $.555^{* * * k}$ & $.660^{\text {kntx }}$ \\
\hline WP $0 ; 9$ & & & & 1 & $.730^{* \ldots \ldots k}$ & $.460^{* * *}$ & $.306^{*}$ & $.336^{*}$ & .215 & $.340^{*}$ & $.322^{*}$ & .227 & .256 & $.291^{*}$ & .208 \\
\hline WP $1 ; 0$ & & & & & 1 & $.787^{* * *}$ & $.569^{* * * *}$ & $.510^{* * *}$ & $.404^{* * * x}$ & $.554^{* * * *}$ & $.484^{* * *}$ & $.357^{*}$ & $.520^{* * * k}$ & $.440^{* * *}$ & $.393^{* * *}$ \\
\hline WP $1 ; 3$ & & & & & & 1 & $.490^{* * *}$ & $.338^{*}$ & $.448^{* * *}$ & $.464^{k * k}$ & $.350^{*}$ & $.327^{*}$ & $.448^{* *}$ & $.291^{*}$ & $.431^{* k}$ \\
\hline TAG $0 ; 9$ & & & & & & & 1 & $.747^{* \ldots * x}$ & $.673^{k \ldots * k}$ & $.870^{* \ldots * x}$ & 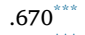 & $.494^{* * i k}$ & $.942^{* \ldots * t}$ & $.664^{k x * x}$ & $.667^{* * * x}$ \\
\hline TAG $1 ; 0$ & & & & & & & & 1 & $.771^{k \text { k玄 }}$ & $.690^{* * * * x}$ & $.744^{* \ldots * k x}$ & $.493^{\operatorname{stkx}}$ & $.687^{* 2 \pi k t}$ & $.957^{* * * k}$ & $.763^{k k^{k * k}}$ \\
\hline TAG $1 ; 3$ & & & & & & & & & 1 & $.686^{k * k * x}$ & $.718^{k+k+k}$ & $.627^{\text {takex }}$ & $.530^{* *}$ & $.663^{k+k / k}$ & $.980^{* k * k}$ \\
\hline EG $0 ; 9$ & & & & & & & & & & 1 & $.751^{k+x+k}$ & $.578^{* k * k}$ & $.654^{* * * *}$ & $.554^{* * * * k}$ & $.661^{\text {kk*k }}$ \\
\hline EG $1 ; 0$ & & & & & & & & & & & 1 & $.787^{3 * k * x}$ & $.517^{* 2 * k e}$ & $.519^{k * k x}$ & $.621^{\text {k⿻*k }}$ \\
\hline EG $1 ; 3$ & & & & & & & & & & & & 1 & $.373^{*}$ & .281 & $.462^{* * *}$ \\
\hline LG $0 ; 9$ & & & & & & & & & & & & & 1 & $.663^{* * * *}$ & $.527^{\text {tikn }}$ \\
\hline LG $1 ; 0$ & & & & & & & & & & & & & & 1 & $.697^{* k * x}$ \\
\hline LG $1 ; 3$ & & & & & & & & & & & & & & & 1 \\
\hline
\end{tabular}

Note $:$ WC $=$ Word comprehension; WP $=$ Word production; TAG $=$ Total actions and gestures; EG = Early gestures; LG $=$ Later gestures

$* p<.05$.

$* * p<.01$.

$* * * \mathrm{p}<.001$.

and early gestures at 1;0 predicted word comprehension at 1;3 (see Fig. 3). Again, word comprehension did not predict the number of early gestures produced three months later.

Model 3 tested the cross-lagged relationships between the number of words comprehended and the number of later gestures produced. The model also had a good fit, $N=46, \chi^{2}(4)=4.826, p=.306, \chi^{2} / \mathrm{df}=1.207$, RMSEA $=.067$ [90\% CI: .000-.241], $\mathrm{CFI}=.996, \mathrm{TLI}=.985$, SRMR $=.037$. The number of later gestures at $0 ; 9$ predicted the number of words comprehended at $1 ; 0$, but no significant path was found from $1 ; 0$ to $1 ; 3$ (see Fig. 4). Once again, word comprehension did not predict later gestures three months later.

Model 4 tested the cross-lagged relationships between the number of words produced and the total number of actions and gestures reported by parents. The model had an acceptable fit, $N=41, \chi^{2}(4)=5.891, p=.207, \chi^{2} / \mathrm{df}=1.473$, RMSEA $=.107$ [90\% CI: $.000-.277]$, CFI $=.989$, TLI $=.960$, SRMR $=.034$. The total number of actions and gestures produced at 0;9 predicted the number of words produced at 1;0, but no other significant prospective relationships between both variables were found (see Fig. 5).

Model 5 tested the cross-lagged relationships between the number of words produced and the number of early gestures produced. The model fitted the data very well, $N=42, \chi^{2}(4)=3.504, p=.477, \chi^{2} / \mathrm{df}=0.876$, RMSEA $=.000$ [90\% CI: .000-.220], $\mathrm{CFI}=1.00$, TLI $=1.01, \mathrm{SRMR}=.023$. The number of early gestures at $0 ; 9$ predicted the number of words produced at $1 ; 0$ (see Fig. 6). No other significant cross-lagged paths were found.

Model 6 tested the cross-lagged relationships between the number of words and the number of later gestures produced. The model had an acceptable fit, $N=46, \chi^{2}(4)=5.976, p=.201, \chi^{2} / \mathrm{df}=1.494$, RMSEA $=.104$ [90\% CI: .000-.263], CFI $=.988$, $\mathrm{TLI}=.957, \mathrm{SRMR}=.033$. Similarly to the two previous models, only one cross-lagged path was significant: the number of early gestures at 0;9 predicted the number of words produced at 1;0 (see Fig. 7).

\section{Discussion and conclusions}

The main goal of this study was to investigate if the relationship between language and communicative gestures is reciprocal, using a longitudinal design in which infants were assessed at three-month intervals from 0;9 to $1 ; 3$.

The first hypothesis stated that the number of actions and gestures produced at $0 ; 9$ and 1;0 predicts the number of words

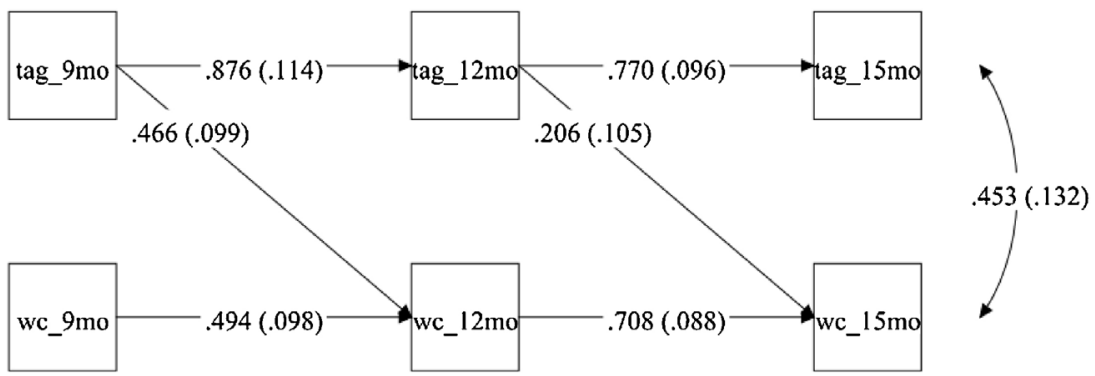

Fig. 2. Cross-lagged relationships between word comprehension (WC) and total number of actions and gestures (TAG) at 0;9 (9 mo), 1;0 (12 mo) and 1;3 (15 mo). Values given are standardized coefficients and standard errors are in parentheses. All the coefficients shown are significant $(p<.05)$. Non-significant coefficients were omitted. 


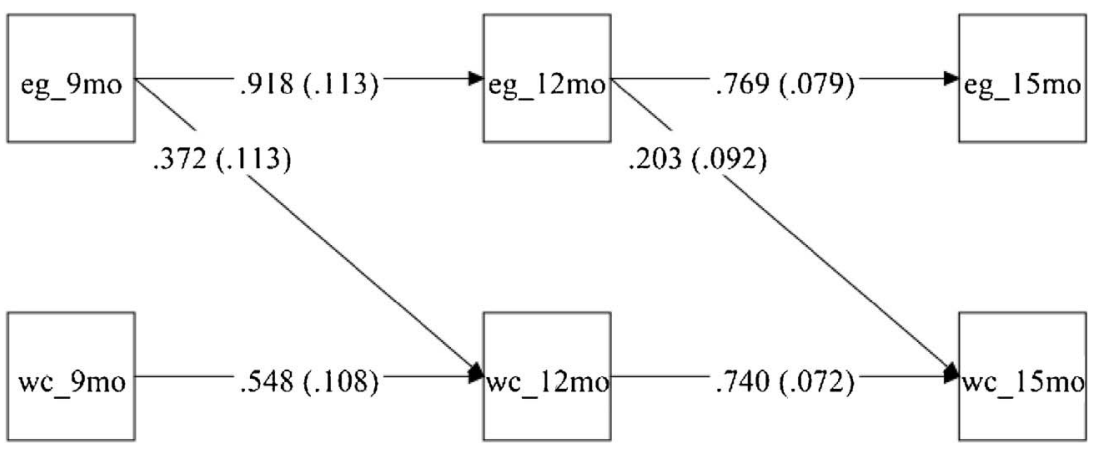

Fig. 3. Cross-lagged relationships between word comprehension (WC) and early gestures (EG) at 0;9 (9mo), 1;0 (12 mo) and 1;3 (15 mo). Values given are standardized coefficients and standard errors are in parentheses. All the coefficients shown are significant $(p<.05)$. Non-significant coefficients were omitted.

comprehended three months later but not the opposite. Overall, our results supported the hypothesis: both the total number of actions and gestures and the number of early gestures at $0 ; 9$ and $1 ; 0$ predicted the number of words comprehended at $1 ; 0$ and $1 ; 3$, respectively. Later gestures at $0 ; 9$ predicted word comprehension at $1 ; 0$ year. Overall, our findings indicate that the predictive power of actions and gestures for word comprehension extends at least up to $1 ; 3$, but our results also highlight that the predictive power of gestures is strongest before the children's first anniversary. When analyzing the opposite relationship, the results of this study indicate that the number of words comprehended was not a predictor of the number of actions and gestures produced three months later by the infants, whether a total score or specific scores for early and later gestures were used. Therefore, although gestures and language seem to share neural substrates, their longitudinal relationships are not reciprocal. Some authors (e.g., Nelson, 2007) have suggested that actions and gestures, as well as symbolic play, help the development of symbolic representation abilities that are essential for language acquisition. Our findings seem to provide additional support for this claim, given that actions and gestures predicted future language comprehension, but not the opposite. Therefore, it is possible that the development of representational abilities is highly dependent of the use of communicative actions and gestures, which explains why gestures are good predictors of the future lexicon size. However, more comprehension skills do not necessarily translate into the acquisition of new gestures. Research has indicated that infants and toddlers seem to learn new gestures and actions mainly through imitation of adults and peers (Hanna \& Meltzoff, 1993; Klein \& Meltzoff, 1999), and thus this observational learning might require a minimum level of linguistic comprehension. Nonetheless, in this study, only the different number of gestures produced was assessed and not the frequency of use of each gesture. Future studies should also consider including one measure of frequency of gesture use.

The second hypothesis of this study was that the number of actions and gestures produced at 0;9 and 1;0 predicts the number of words produced three months later, but not the opposite. This hypothesis was partially supported by our data. Word production was only predicted at 1;0 year, whenever early gestures, later gestures or total number of actions and gestures was considered at $0 ; 9$. Actions and gestures at 1;0 year did not predict word production at 1;3. These findings highlight the importance not only of early gestures, which are already frequent at 0;9 (Bates et al., 1979; Bates \& Dick, 2002; Brooks \& Meltzoff, 2008), but also of later gestures, which are more scarce at early ages, for word production. Our results seem to support the claim that the earlier the child produces recognitory gestures (here labeled as later gestures) the earlier the child will start talking (Shore et al., 1990), given that the children who already show some recognitory gestures at 0;9 have an higher probability of producing more words at 1;0 year. Research with atypical populations, such as Down or Williams syndrome suggests that the appearance of recognitory gestures is a pre-requisite for word production (Bates \& Dick, 2002). Our findings indicate that the importance of this object-related actions for language onset can be similar for typically developing children, given that the predictive power of actions and gestures was limited to the period 0;9-1;0. Another major finding of our study was that, similarly to word comprehension, word production did not predict actions and gestures at any time. Therefore, our findings are consistent with the ones obtained by Carpenter et al. (1998), although different methodologies have been used in both studies (direct observation versus parental reports; words referring only to concrete objects or actions versus all categories of words).

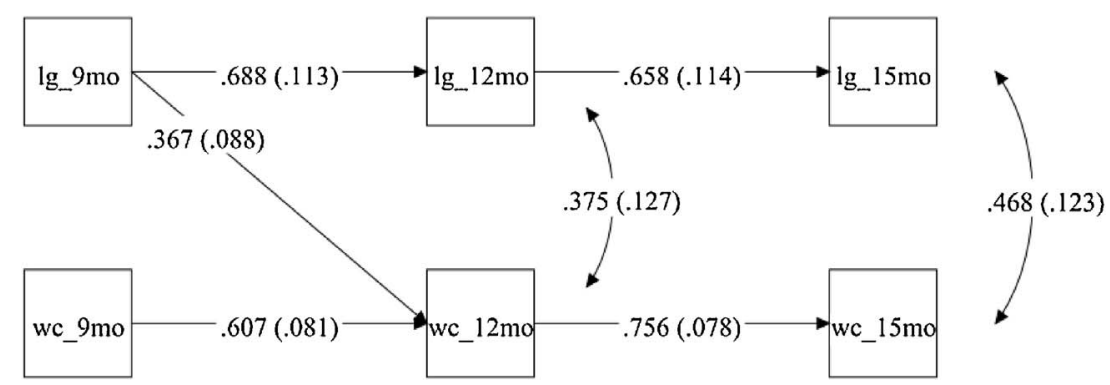

Fig. 4. Cross-lagged relationships between word comprehension (WC) and later gestures (LG) at 0;9 (9 mo), 1;0 (12 mo) and 1;3 (15 mo). Values given are standardized coefficients and standard errors are in parentheses. All the coefficients shown are significant $(p<.05)$. Non-significant coefficients were omitted. 


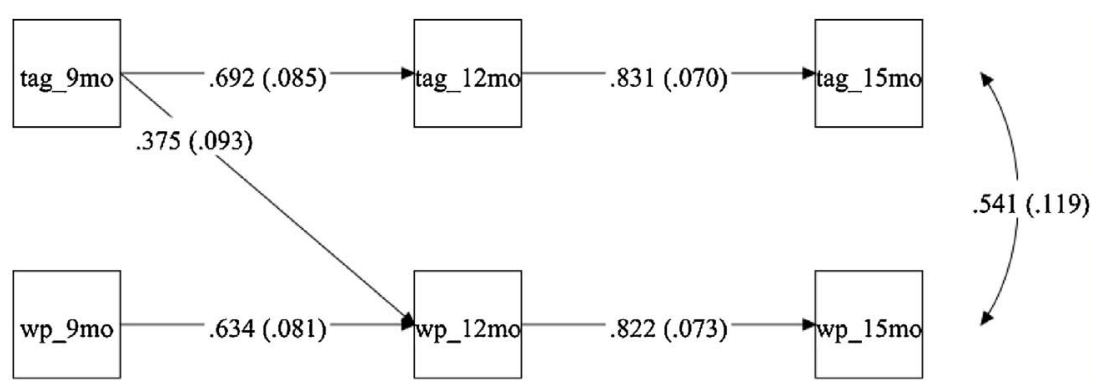

Fig. 5. Cross-lagged relationships between word production (WP) and total number of actions and gestures (TAG) at 0;9 (9 mo), 1;0 (12 mo) and 1;3 (15 mo). Values given are standardized coefficients and standard errors are in parentheses. All the coefficients shown are significant ( $p<.05)$. Non-significant coefficients were omitted.

The third hypothesis of this study stated that the total number of actions and gestures, the number of early gestures and the number of later gestures are strongest predictors of the number of words comprehended than of the number of words produced. Our findings did not support this hypothesis, contrarily to other studies which have consistently found a stronger relationship between gestures and comprehension than with production (Bavin et al., 2008; Caselli et al., 2012; Fenson et al., 2007; Kern, 2007). The differences in the statistical methods used can potentially explain the differences in the findings. Most of these studies simply performed bivariate correlations between the variables. In our study if considered only the results of the Pearson correlations, the relationships between actions and gestures (total, early gestures and later gestures) and word comprehension are slightly stronger than the ones between actions and gestures and word production. However, when analyzed the results of the cross-lagged models, where the level of competence in all variables at the previous time points is taken into account, no meaningful differences in the size of the relationships between actions and gestures, word comprehension and word production were found.

The main limitation of the present study is that information regarding actions and gestures and language skills was collected using only parental reports. Although a large corpus of research on the relationship between communicative gestures and spoken language has used the CDI for data collection (Alcock \& Krawczyk, 2010; Caselli et al., 2012; Kern, 2007; Kraljević et al., 2014; Sansavini et al., 2011), and the parental reports have been demonstrated to be valid and reliable (Fenson et al., 2007; Pérez-Pereira \& Resches, 2011; Silva et al., 2017), future studies should also use direct measures of the infants' communicative skills in order to cross-validate the findings using varied methodologies. Another limitation is related with the sample used in this study: although the sample is representative of the population, its size is relatively low. A third limitation is related to the fact that no subtypes of gestures or lexical categories in word production and comprehension were analyzed, although research results have shown some variability in the rate of acquisition of different subtypes. For example, several studies found that deictic gestures (included in the early gestures dimension) and social words are acquired especially early when compared to other types of gestures and semantic lexical categories, which can be explained by their frequent use in daily contexts and its connection with social routines (Kern, 2007; Sansavini et al., 2010; Stolt, Haataja, Lapinleimu, \& Lehtonen, 2008). Moreover, the cross-sectional study by Kraljević et al. (2014) found that the production of open-class words is better predicted by object-related actions, whereas the production of closed-class words and social terms is better predicted by routine gestures. These findings should be considered in future studies when analyzing the cross-lagged relationships between actions and gestures and language, by exploring the interrelationship between different lexical categories and subtypes of communicative actions and gestures.

\section{Funding}

This research was mainly conducted at the Research Centre on Child Studies (UID/CE/00317/2013), University of Minho, and was supported by the European Regional Development Fund (FEDER) through the European programme COMPETE (Operational

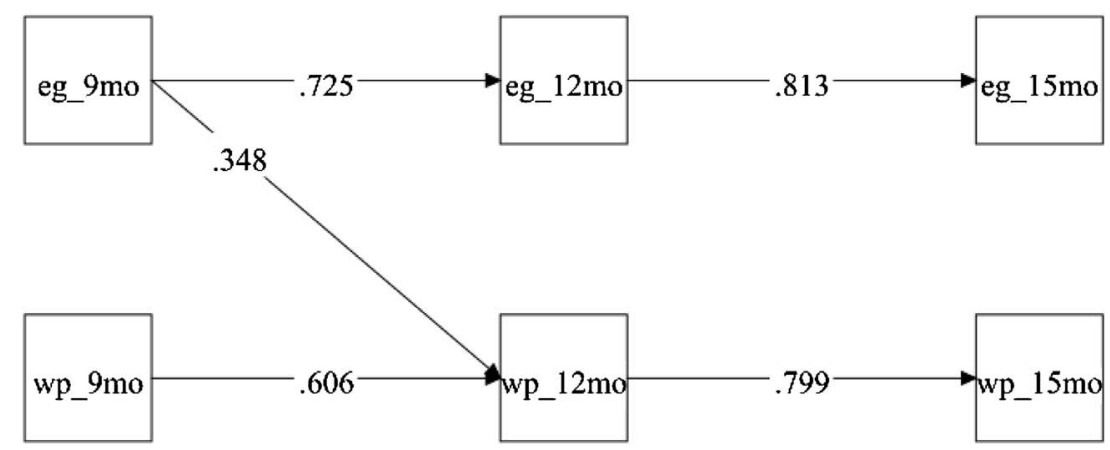

Fig. 6. Cross-lagged relationships between word production (WP) and early gestures (EG) at 0;9 (9 mo), 1;0 (12 mo) and 1;3 (15 mo). Values given are standardized coefficients and standard errors are in parentheses. All the coefficients shown are significant $(p<.05)$. Non-significant coefficients were omitted. 


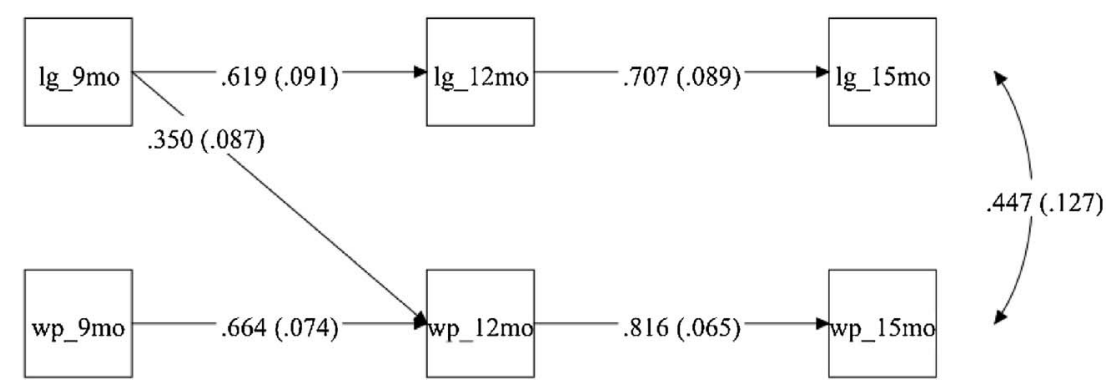

Fig. 7. Cross-lagged relationships between word production (WP) and later gestures (LG) at 0;9 (9 mo), 1;0 (12 mo) and 1;3 (15 mo). Values given are standardized coefficients and standard errors are in parentheses. All the coefficients shown are significant $(p<.05)$. Non-significant coefficients were omitted.

Programme for Competitiveness Factors) under the National Strategic Reference Framework (QREN) - FCOMP-01-0124-FEDER029556 and by FCT (Fundação para a Ciência e a Tecnologia PTDC/MHC-PED/4725/2012). Part of the study was also conducted at the Psychology Research Centre (UID/PSI/01662/2013), University of Minho, and supported by the FCT and the Portuguese Ministry of Science, Technology and Higher Education through national funds and co-financed by FEDER through COMPETE2020 under the PT2020 Partnership Agreement (POCI-01-0145-FEDER-007653). The first and the second authors are also supported by grants SFRH/ BPD/102549/2014 and SFRH/BD/86795/2012 from FCT.

\section{References}

Alcock, K. J., \& Krawczyk, K. (2010). Individual differences in language development: Relationship with motor skill at 21 months. Developmental Science, 13(5), 677-691. http://dx.doi.org/10.1111/j.1467-7687.2009.00924.x.

Bates, E., Benigni, L., Bretherton, I., Camaioni, L., \& Volterra, V. (1979). The emergence of symbols: Cognition and communication in infancy. New York: Academic Press. Bates, E., \& Dick, F. (2002). Language, gesture, and the developing brain. Developmental Psychobiology, 40(3), 293-310. http://dx.doi.org/10.1002/dev.10034.

Bates, E., Marchman, V., Thal, D., Fenson, L., Dale, P. S., Reznick, S., ..., \& Hartung, J. (1994). Developmental and stylistic variation in the composition of early vocabulary. Journal of Child Language, 21, 85-123.

Bates, E., Thal, D., Whitesell, K., Fenson, L., \& Oakes, L. (1989). Integrating language and gesture in infancy. Developmental Psychology, 25(6), 1004-1019. http://dx. doi.org/10.1037/0012-1649.25.6.1004.

Bavin, E. L., Prior, M., Reilly, S., Bretherton, L., Williams, J., Eadie, P., ..., \& Ukoumunne, O. C. (2008). The Early Language in Victoria Study: predicting vocabulary at age one and two years from gesture and object use. Journal of Child Language, 35(3), 687-701. http://dx.doi.org/10.1017/S0305000908008726.

Bleses, D., Vach, W., Slott, M., Wehberg, S., Thomsen, P., Madsen, T. O., \& Basbøll, H. (2008a). Early vocabulary development in Danish and other languages: a CDIbased comparison. Journal of Child Language, 35(3), 619-650. http://dx.doi.org/10.1017/S0305000908008714.

Bleses, D., Vach, W., Slott, M., Wehberg, S., Thomsen, P., Madsen, T. O., \& Basbøll, H. (2008b). The Danish Communicative Developmental Inventories: Validity and main developmental trends. Journal of Child Language, 35(3), 651-669. http://dx.doi.org/10.1017/S0305000907008574.

Bollen, K. A. (1989). Structural equation models with latent variables. New York: Wiley.

Brooks, R., \& Meltzoff, A. N. (2008). Infant gaze following and pointing predict accelerated vocabulary growth through two years of age: a longitudinal, growth curve modeling study. Journal of Child Language, 35(1), 207-220. http://dx.doi.org/10.1017/S030500090700829X.

Browne, M. W., \& Cudeck, R. (1993). Alternative ways of assessing model fit. In K. A. Bollen, \& J. S. Long (Eds.), Testing structural equation models (pp. 136-162). Beverly Hills, CA: Sage.

Capone, N. C., \& McGregor, K. K. (2004). Gesture development: A review for clinical and research practices. Journal of Speech Language and Hearing Research, 47(1), 173-186. http://dx.doi.org/10.1044/1092-4388(2004/015).

Carpenter, M., Nagell, K., \& Tomasello, M. (1998). Social cognition, joint attention, and communicative competence from 9 to 15 months of age. Monographs of the Society for Research in Child Development, 63(4) Serial No 255.

Caselli, M. C., Rinaldi, P., Stefanini, S., \& Volterra, V. (2012). Early action and gesture "vocabulary" and its relation with word comprehension and production. Child Development, 83(2), 526-542. http://dx.doi.org/10.1111/j.1467-8624.2011.01727.x.

Fenson, L., Marchman, V., Thal, D., Dale, P. S., Reznick, J., \& Bates, E. (2007). MacArthur-Bates communicative development inventories: Users guide and technical manual (2nd edition). Baltimore: Paul H Brookes.

Gentilucci, M., \& Dalla Volta, R. (2007). The motor system and the relationships between speech and gesture. Gesture, 7(2), $159-177$.

Hanna, E., \& Meltzoff, A. N. (1993). Peer imitation by toddlers in laboratory, home, and day-care contexts: Implications for social learning and memory. Developmental Psychology, 29(4), 701-710. http://dx.doi.org/10.1037/0012-1649.29.4.701.

Hoyle, R. H., \& Panter, A. T. (1995). Writing about structural equation models. In R. H. Hoyle (Ed.), Structural equational modeling: Concepts, issues, and applications (pp. 158-176). Thousand Oaks, CA: Sage Publications.

Hu, L., \& Bentler, P. M. (1999). Cutoff criteria for fit indexes in covariance structure analysis: Conventional criteria versus new alternatives. Structural Equation Modeling: A Multidisciplinary Journal, 6(1), 1-55.

Iverson, J. M., \& Goldin-Meadow, S. (2005). Gesture paves the way for language development. Psychological Science, 16(5), 367-371.

Jackson-Maldonado, D. J., Thal, D., Marchman, V., Fenson, L., Newton, T., \& Conboy, B. T. (2003). CDI Inventarios MacArthur-Bates del Desarrollo de Habilidades Comunicativas [CDI MacArthur-Bates Communicative Development Inventories]. Baltimore, MD: Brookes Publishing.

Kern, S. (2007). Lexicon development in French-speaking infants. First Language, 27(3), 227-250. http://dx.doi.org/10.1177/0142723706075789.

Klein, P. J., \& Meltzoff, A. N. (1999). Long-term memory, forgetting, and deferred imitation in 12- month-old infants. Developmental Science, 2(1), 102-113. http://dx. doi.org/10.1111/1467-7687.00060.

Kraljević, J. K., Cepanec, M., \& Šimleša, S. (2014). Gestural development and its relation to a child's early vocabulary. Infant Behavior and Development, 37(2), 192-202. http://dx.doi.org/10.1016/j.infbeh.2014.01.004.

López-Ornat, S., Gallego, C., Gallo, P., Karousou, A., Mariscal, S., \& Martínez, M. (2005). Inventario de Desarrollo Comunicativo MacArthur. Madrid: TEA Ediciones, S.A.

Muthén, L. K., \& Muthén, B. O. (2012). Mplus user's guide (Seventh edition). Los Angeles, CA: Muthén \& Muthén.

Nelson, K. (2007). Young minds in social worlds: Experience, meaning, and memory. Cambridge: Harvard University Press.

Pérez-Pereira, M., \& Resches, M. (2011). Concurrent and predictive validity of the Galician CDI. Journal of Child Language, 38(1), 121-140. http://dx.doi.org/10.1017/ S0305000909990262.

Sansavini, A., Bello, A., Guarini, A., Savini, S., Stefanini, S., \& Caselli, M. C. (2010). Early development of gestures, object-related actions, word comprehension and word production, and their relationships in Italian infants: A longitudinal study. Gesture, 10(1), 52-85. http://dx.doi.org/10.1075/gest.10.1.04san.

Sansavini, A., Guarini, A., Savini, S., Broccoli, S., Justice, L., Alessandroni, R., \& Faldella, G. (2011). Longitudinal trajectories of gestural and linguistic abilities in very 
preterm infants in the second year of life. Neuropsychologia, 49, 3677-3688.

Schermelleh-Engel, K., Moosbrugger, H., \& Müller, H. (2003). Evaluating the fit of structural equation models: Tests of significance and descriptive goodness-of-fit measures. Methods of Psychological Research Online, 8(2), 23-74.

Selig, J. P., \& Little, T. D. (2012). Autoregressive and cross-lagged panel analysis for longitudinal data. In B. Laursen, T. D. Little, \& N. A. Card (Eds.), Handbook of developmental research methods (pp. 265-278). New York: Guilford Press.

Shore, C., Bates, E., Bretherton, I., Beeghly, M., \& O’Connell, B. (1990). Vocal and gestural symbols: Similarities and differences from 13 to 28 months. In V. Volterra, \& C. J. Erting (Eds.), From gesture to language in hearing and deaf children (pp. 79-91). Berlin, Heidelberg: Springer Berlin Heidelberg. http://dx.doi.org/10.1007/9783-642-74859-2 8 .

Silva, C., Cadime, I., Ribeiro, I., Acosta, V., Lima, R., \& Viana, F. L. (2017). Communicative development of Portuguese infants aged between 8 and 15 months. Revista de Logopedia, Foniatría Y Audiología. http://dx.doi.org/10.1016/j.rlfa.2016.12.001.

Stolt, S., Haataja, L., Lapinleimu, H., \& Lehtonen, L. (2008). Early lexical development of Finnish children: A longitudinal study. First Language, 28(3), 259-279. http:// dx.doi.org/10.1177/0142723708091051.

Wehberg, S., Vach, W., Bleses, D., Thomsen, P., Madsen, T. O., \& Basboll, H. (2007). Danish children's first words: Analysing longitudinal data based on monthly CDI parental reports. First Language, 27(4), 361-383. http://dx.doi.org/10.1177/0142723707081723. 